\title{
Energy modernization of housing stock
}

\author{
Svetlana Ovchinnikova ${ }^{*}$, Michail Kalinichenko ${ }^{2}$, Nina Markina $^{3}$, and Elena Schneider $^{3}$ \\ ${ }^{1}$ I. T. Trubilin Kuban State Agrarian University, Kalinin St., 13, Krasnodar, 350000, Russia \\ ${ }^{2}$ North-Caucasus Federal University, Pushkina St., 1, Stavropol, 355017, Russia \\ ${ }^{3}$ State Humanitory and Technical Institute, Mira Blvd., 18, Nevinnomyssk, 357108, Russia
}

\begin{abstract}
The tasks of resource and energy saving in the housing and communal environment of districts, the search for the most favorable development in the control of the technical condition of the housing stock are the focus of many foreign and domestic studies. This paper presents a review of the problem of energy modernization of the housing stock. In the context of the research problem, the housing sector will be considered by analyzing several conditions. The identification of predominantly influencing factors that affect the transformation of changes in the housing stock is of crucial importance. A clear definition of these ratios within the system under study leads to accurate accounting and forecasting of the state of the housing stock. When studying the issue of energy modernization of residential real estate, it is important to differentiate and streamline, taking into account economic indicators, the composition and structure of works. A mathematical model for optimizing the modernization process using dynamic programming methods is presented. Based on the scheme of dynamic planning for the most appropriate allocation of funds for energysaving measures in general, a method for the most favorable regulation of the housing stock has been created. Energy modernization of the housing stock leads to a reduction in spending on housing and communal services, and contributes to improving comfortable living conditions for citizens.
\end{abstract}

\section{Introduction}

The main issues of social and economic innovations are the formation, modernization and development of the housing environment. The reasons that hold back the mass introduction of energy-efficient houses are the lack of additional costs for developers to increase the efficiency of residential buildings [1-3]. Additional costs are 10-25\% of the estimated cost. In this case, only the increase in the cost of capital investments is taken into account.

When considering the benefits of such construction, therefore, it would be correct to proceed from the calculation of the reduced costs (capital investment plus operating costs) of the building's life cycle. Here, the efficiency for the economy as a whole is obvious in the form of the benefits obtained from saving resources, not to mention the social effect of reducing utility payments to the population. Additionally, the costs incurred for these activities are paid off in a fairly short time (5-8 years). Studies have shown that the modernization of the housing stock is of priority importance for improving the quality of

* Corresponding author: svetlana.swetlana-ov@ yandex.ru 
human life [4].

About $30 \%$ of energy losses occur "inside the house" and in order to avoid them, you will need not only individual measures for energy saving, but also major comprehensive repairs using energy-saving technologies.

The first thing to do before upgrading the facility is, of course, to conduct an energy audit. It will allow identifying heat losses and electricity overruns, and determining what and how to reduce energy consumption.

In general, there is no universal recipe for energy modernization. Everything is very individual, depending on the condition of the building, its internal and external communications. Only a comprehensive solution is possible. One cannot say that it is necessary to change the windows, and not to put a heat node or insulate the walls, everything is determined together.

At the same time, in one case, the installation of an individual heating point will save about $5 \%$ on heating, and in the other - as much as $20 \%$. The same applies to wall insulation, replacement of windows and doors. On one object, such measures will reduce heating costs by $20-25 \%$, and on the other-by $40-50 \%$.

If we talk about payback, investments aimed at reducing energy consumption are returned most quickly. For example, replacing traditional incandescent lamps with led lighting can reduce electricity consumption by 15 times. And the payback period is only $1.5-2$ years. The purchase and installation of an individual heating point pays for itself within 2-3 years.

It should be also paid attention to the technical condition of the infrastructure and apartments separately. The issue of conducting a technical audit of the housing stock is rather political and requires changes to 10 laws and regulations that are currently simply impossible.

Replacing conventional light lamps with led lamps. The easiest way to save money, which almost everyone starts with. Installing led lamps is not the most expensive process, but it gives a serious result. Installing an individual heating point is not the most expensive process, but it gives a serious result. As well as replacing windows in entrances and major repairs of the entrance group with the installation of a vestibule door, and so on.

Updating the housing environment is one of the directions of Russia's housing policy. Following this, the modernization of the housing stock is not only relevant, but also of fundamental importance for its effective implementation. Currently, the housing sector requires special attention from the State, which should regulate the process of its continuous development.

The issues of energy and resource saving in the housing and communal sector of the regions, the optimal process of solving problems on the technical condition of the housing stock are considered by such researchers as V. Y. Mishchenko, S. G. Sheina, L. N. Chernysheva, E. G. Gasho, D. Wolfberg, G. Aslanyan, G. S. Ivanova, V. V. Klimenko, and others [5].

Scientific and methodological foundations of research on reproduction policy in the housing sector are widely reflected in the works of S. A. Bolotin, A.V. Afanasiev, K. A. Bagrinovsky, O. E. Bessonova, A. P. Ivanov, Y. A. Kulikov, V. F. Kasyanov, A.N. Kirillova, N.B. Kosareva, Y. N. Kulakov, M.S. Budnikov, A.V. Ginzburg, P. G. Grabovoi, B.V. Prykin, V. M. Serov, S.B. Sivaev, S.R. Khachatryan, A.A. Gusakov, E. A. Gusakova, N. I. Ilyina, V. Y.Lyubovnyi, S.V. Nikolaev, V.Y. Ostashko, and others [6-7].

\section{Methods and materials}

The method of solving the problem of energy saving in the housing stock and improving the efficiency of saving, the method of dynamic programming (planning), which was founded by the American mathematician R. Bellman, is used for the first time [8]. The presented method makes it possible to achieve an increase in the economic effect of implementing 
energy-saving measures.

Under the concept of energy modernization of the housing stock, we will take measures for energy saving in the implementation of repair and construction works with its comprehensive update [9-10]. It should be noted that energy modernization is the introduction of various forms of energy-saving technologies into the operation of the housing stock to increase the energy and economic efficiency of this project (figure 1).
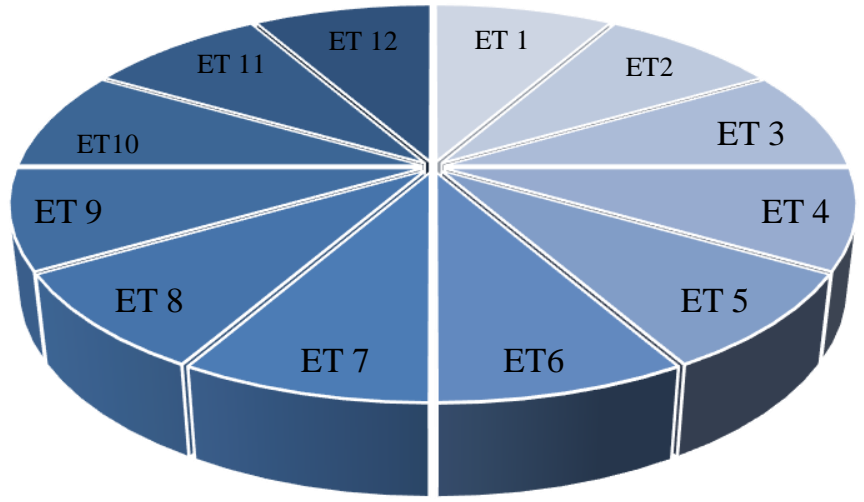

Fig. 1. Structure of energy modernization of housing stock

The economic effect of the energy-saving procedure is directly related to the selection of special technological measures for the modernization of housing and the organization of ongoing work [11-12].

Let's define some types of energy saving measures:

- $\quad$ installing windows (ET1);

- $\quad$ automated light sources in public areas (ET2);

- $\quad$ organization of an automated heat point (ET3);

- use of automatic door closers on entrance doors (ET 4);

- use of automatic sensor mixers (ET 5);

- changing the thermal protection properties of building envelope structures (walls) (ET 6);

- $\quad$ changing the thermal protection properties of the roof (ET 7);

- $\quad$ insulation of external doors (ET 8);

- $\quad$ the use of motion sensors (9 ET);

- mounting of heat-reflecting structures behind radiators (ET 10);

- thermal insulation (restoration of thermal insulation) of heating, water supply, pipeline in unheated attics and basements (ET11);

- cleaning of the heating system pipeline, reducing hydraulic and heat losses by removing internal scurf from the surfaces of radiators and distribution pipelines (ET 12).

In the process of the study, we decided to analyze received by the study results the issue of planning work on energy modernization with the use of two types of energy-saving measures 1 and 2 for a period of $t$ years.

The amount of capital $\mathrm{x}$ invested in activity 1 , provides a profit for one year

$$
f(x)=A \cdot x
$$

as a result, it is reduced to

$$
\varphi(x) \mathrm{A}^{\prime} \cdot \mathrm{x}
$$


the amount of capital y, included in activity 2, provides a profit for one year

and it comes down to less

$$
g(y)=B \cdot y
$$

$$
\psi(y)=\mathrm{B}^{\prime} \cdot \mathrm{y} \quad \mathrm{b}
$$

Resources $Z_{0}$ should be allocated between activities 1 and 2 for each year of the planned period.

Conditional optimal management $x_{m}^{*}$ at the last step (the amount of funds allocated to activity 1 is found as the value $x_{m}$ at which the revenue reaches the maximum at the last step):

where,

$$
W_{m}^{*}\left(Z_{m-1}\right)=\max _{0 \leq x_{m} \leq Z_{m-1}}\left\{w_{m}\left(Z_{m-1}, x_{m}\right)\right\}
$$

$$
W_{m}\left(Z_{m-1}, x_{m}\right)=A \cdot x_{m}+B \cdot\left(Z_{m-1}, x_{m}\right)=(A-B) \cdot x_{m}+B \cdot Z_{m-1}, A \neq B
$$

The graph of the function $W_{m}=W_{m}\left(Z_{m-1}, x_{m}\right)$, depending on the argument $x_{m}$, is displayed when a certain $Z_{m-1}$ graph is set (Fig.2, 3).

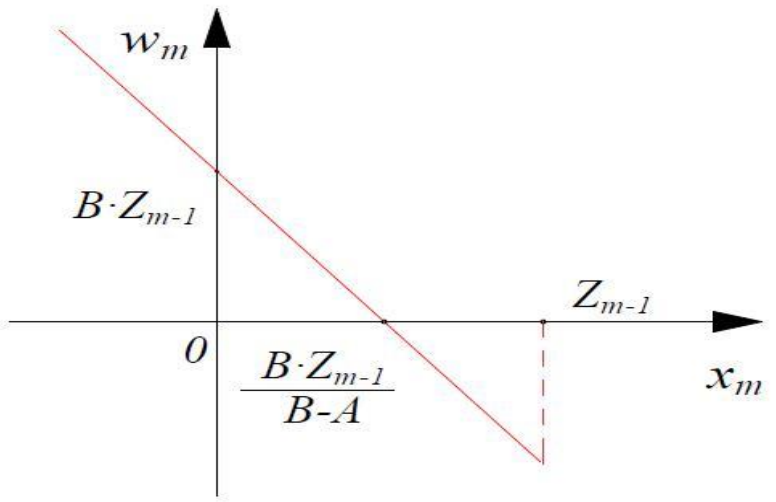

Fig. 2. Graph of the function $W_{m}=W_{m}\left(Z_{m-1}, x_{m}\right)$ for $\mathrm{B}>\mathrm{A}$;

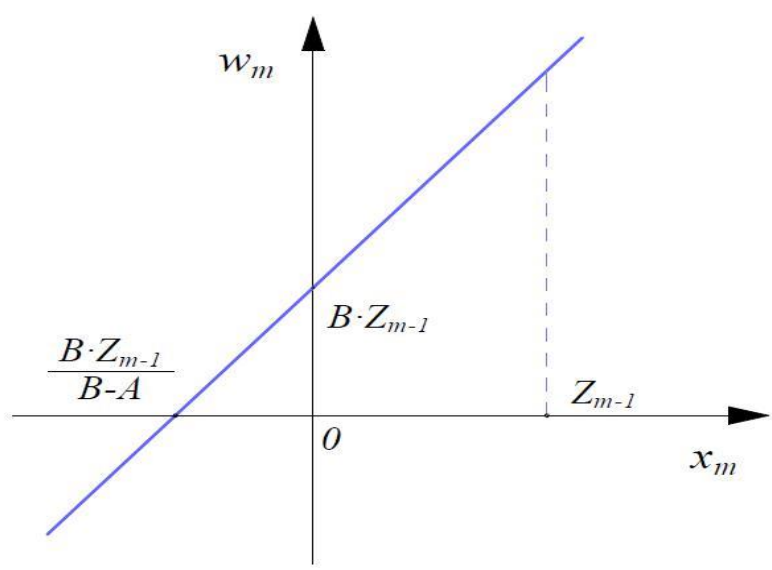

Fig. 3. Graph of the function $W_{m}=W_{m}\left(Z_{m-1}, x_{m}\right)$ for $\mathrm{B}<\mathrm{A}$

The highest value can only be reached at intermediate boundaries $\left(0, Z_{m-1}\right)$.

To find a certain boundary, follow the formula (5) $x_{m}=0$ and $x_{m}=Z_{m-1}$

In the second case, when $x_{m} Z_{m-1}$ the maximum value of function $\mathrm{w}_{\mathrm{m}}$ is reached, it is 
equal to the value $A \cdot Z_{m-1}$.

Therefore, the maximum income at the last step does not depend on $Z_{m-1}$ and its value depends on the values $\mathrm{A}$ and $\mathrm{B}$, which means that at the beginning of the last year, all available funds should be invested in event 1 at $B<A$ or in event 2 at $B>A$.

This is natural, since the income from the selected event is greater, and we are no longer interested in spending money (there will be no next step).

With this optimal management, the last year will bring us income $W_{m}=B \cdot Z_{m-1}$ or $W_{m}=A \cdot Z_{m-1}$. We will move to the distribution of funds for the (t-1)th year. Let us approach it with a reserve of funds $Z_{m-2}$. Let's find the conditional maximum income for the last two years:

$$
W_{m}^{*}\left(Z_{m-2}\right)=\max _{0 \leq x_{m-1} \leq Z_{m-2}}\left\{A \cdot x_{m-1}+B \cdot\left(Z_{m-2}-x_{m-1}\right)+W_{m}^{*}\left(Z_{m-1}\right)\right\}
$$

But

$$
Z_{m-1}=\mathrm{A}^{\prime} \cdot x_{m-1}+\mathrm{B}^{\prime} \cdot\left(Z_{m-2}-x_{m-1}\right)
$$

and, therefore,

$$
W_{m}^{*}\left(Z_{m-1}\right)=B \cdot\left(\mathrm{A}^{\prime} \cdot x_{m-1}+\mathrm{B}^{\prime} \cdot\left(Z_{m-2}-x_{m-1}\right)\right)
$$

or

$$
W_{m}^{*}\left(Z_{m-1}\right)=A \cdot\left(\mathrm{A}^{\prime} \cdot x_{m-1}+\mathrm{B}^{\prime} \cdot\left(Z_{m-2}-x_{m-1}\right)\right)
$$

From here we get

$$
\begin{array}{r}
W_{m-1, m}^{*}\left(Z_{m-2}\right)=\max _{0 \leq x_{m-1} \leq Z_{m-2}}\left\{A \cdot x_{m-1}+B \cdot\left(Z_{m-2}-x_{m-1}\right)+A \cdot\left(A^{\prime} \cdot x_{m-1}+B^{\prime} .\right.\right. \\
\left.\left.\left(Z_{m-2}-x_{m-1}\right)\right)\right\}
\end{array}
$$

or

$$
\begin{array}{r}
W_{m-1, m}^{*}\left(Z_{m-2}\right)=\max _{0 \leq x_{m-1} \leq Z_{m-2}}\left\{A \cdot x_{m-1}+B \cdot\left(Z_{m-2}-x_{m-1}\right)+B \cdot\left(A^{\prime} \cdot x_{m-1}+B^{\prime} .\right.\right. \\
\left.\left.\left(Z_{m-2}-x_{m-1}\right)\right)\right\}(12)
\end{array}
$$

The expression in curly brackets is again a polynomial of the first degree relative $\mathrm{x}_{\mathrm{m}-1}$, and its graph is a straight line; the function, based on the obtained parameters, can be increasing or decreasing (figure 2,3): $\mathrm{x}_{\mathrm{m}-1}=0$ и $\mathrm{x}_{\mathrm{m}-1}=\mathrm{Z}_{\mathrm{m}-2}$.

in first case (at $\mathrm{x}_{\mathrm{m}-1}=0$ ) we get

$$
W_{m-1, m}^{*}\left(Z_{m-2}\right)=\left(B+A \cdot B^{\prime}\right) \cdot Z_{m-2}
$$

or

$$
\mathrm{W}_{\mathrm{m}-1, \mathrm{~m}}^{*}\left(\mathrm{Z}_{\mathrm{m}-2}\right)=\left(1+\mathrm{B}^{\prime}\right) \cdot \mathrm{B} \cdot \mathrm{Z}_{\mathrm{m}-2}
$$

in second case $\left(\right.$ at $\left.\mathrm{x}_{\mathrm{m}-1}=\mathrm{Z}_{\mathrm{m}-2}\right) \mathrm{W}_{\mathrm{m}-1, \mathrm{~m}}^{*}\left(\mathrm{Z}_{\mathrm{m}-2}\right)=\left(1+\mathrm{A}^{\prime}\right) \cdot \mathrm{A} \cdot \mathrm{Z}_{\mathrm{m}-2}$

or

$$
\mathrm{W}_{\mathrm{m}-1, \mathrm{~m}}^{*}\left(\mathrm{Z}_{\mathrm{m}-2}\right)=\left(\mathrm{A}+\mathrm{A}^{\prime} \cdot \mathrm{B}\right) \cdot \mathrm{Z}_{\mathrm{m}-2}
$$

From where it is clear that the maximum "income" depends on the values of the values: A, B, A', B'.

Let's go to (m-2)-th step. Here you need to maximize the value $\mathrm{W}_{\mathrm{m}-2, \mathrm{~m}-1, \mathrm{~m}}^{*}\left(\mathrm{Z}_{\mathrm{m}-3}\right)$ by a similar principle.

Thus, the optimal control will be found. 
Note that this solution will be obtained regardless of the number of steps $t$ or the initial stock of funds $\mathrm{Z}_{0}$

Let's assume that the amount of money allocated for energy modernization of the housing stock is C, RUB. For energy modernization, we will allocate 4 enlarged types of energysaving technologies $(n=4)$. Activities that can be interchanged are considered separately [13].

As the most important information for the development of the model and its solution, we will select a number of properties: types of activities and their specific cost; tariffs for utility services; energy and economic efficiency. We also plan to create a fund of reserve funds that will be used for carrying out repair and construction works that do not provide for energysaving effects, such as finishing works, work on updating the area around the objects under consideration, and other works. The accumulation of funds in the created fund will go as a percentage of funds from the economic effect of energy modernization of the housing stock [14-15].

\section{Results}

The presented method of comprehensive assessment of the effectiveness of energy-saving measures helps to increase the quality of obtaining the conclusion on the restoration of housing stock renewal, increase its energy efficiency; the use of mathematical modeling methods helps to implement the project of financial allocation in such a way that the implementation of organizational and technological solutions for the sequential implementation of measures will lead to the maximum positive social and economic effect.

The developed mathematical model allows maximizing the number of high-quality housing by implementing energy-saving and other measures for the modernization of the housing stock. The problem of updating the housing stock is analyzed. The concept of energy modernization of housing stock was introduced. The main energy-saving technologies in housing modernization are highlighted. The scheme of optimal allocation of funds for energy-saving measures is given. It is assumed that the optimal solution is obtained regardless of the number of steps and the initial stock of invested funds. Based on the proposed algorithm and optimized software package, a numerical experiment was performed. The use and implementation of ET allows increasing the savings of heat and electricity. For example, upgrading the thermal protection properties of the roof allows to increase energy savings by $8-12 \%, 6-15 \%$ - by increasing the thermal protection of windows and exterior doors (below are calculations of energy efficiency). Data on energy-saving measures are determined from algorithms for calculating their efficiency. Economic efficiency calculation of the installation of windows (ET 1):

where:

$$
x_{i 1}=\left(\frac{1}{R_{o}}-\frac{1}{R^{\prime}}\right) * F *\left(t_{v}-t_{n a r}^{s r}\right) * 10^{-3} * \mathrm{~T} * \mathrm{k} * \mathrm{C}
$$

F (m2)- glazing area;

$R_{o}$ - resistance to heat transfer of translucent fences before installing the film; $=0.4$ );

$R_{o}\left(m^{2} *{ }^{0} \mathrm{C} / w\right.$

$t_{v}$ - estimated internal air temperature;

$t_{\text {nar }}^{\text {sr }}$ - average outdoor temperature during the heating period;

C (RUB/Gcal) - heat energy tariff;

$\mathrm{T}(\mathrm{h})$ - duration of the heating period;

$\mathrm{k}$ - coefficient of conversion of $\mathrm{kW} * \mathrm{~h}$ to Gcal, equal to $1.163 \times 10-3$;

$\mathrm{R}^{\prime}\left(\mathrm{M}^{2} * w\right)$ - resistance to heat transfer of translucent fences after installing the film, $\mathrm{R}^{\prime}=0.54$ )

Economic calculation automated light sources in public areas (ET 2): 


$$
x_{i 2}=\left(P_{1} * t_{1}-P_{2} * t_{2}\right) * n * T * 10^{-6} * C
$$

where

$\mathrm{n}$ - is the number of incandescent lamps in places where people are temporarily staying;

$P_{1}$ - incandescent lamp power;

$t_{1}(\mathrm{~h})$ - operating time of the lighting system;

$\mathrm{T}$ - number of working days per year;

$P_{2}$ - power of a compact fluorescent lamp;

$t_{2}(\mathrm{~h})$ - operating time of the lighting system after the installation of motion and presence sensors;

$\mathrm{C}(\mathrm{RUB} / \mathrm{kW} \cdot \mathrm{h})$ - tariff for electric energy.

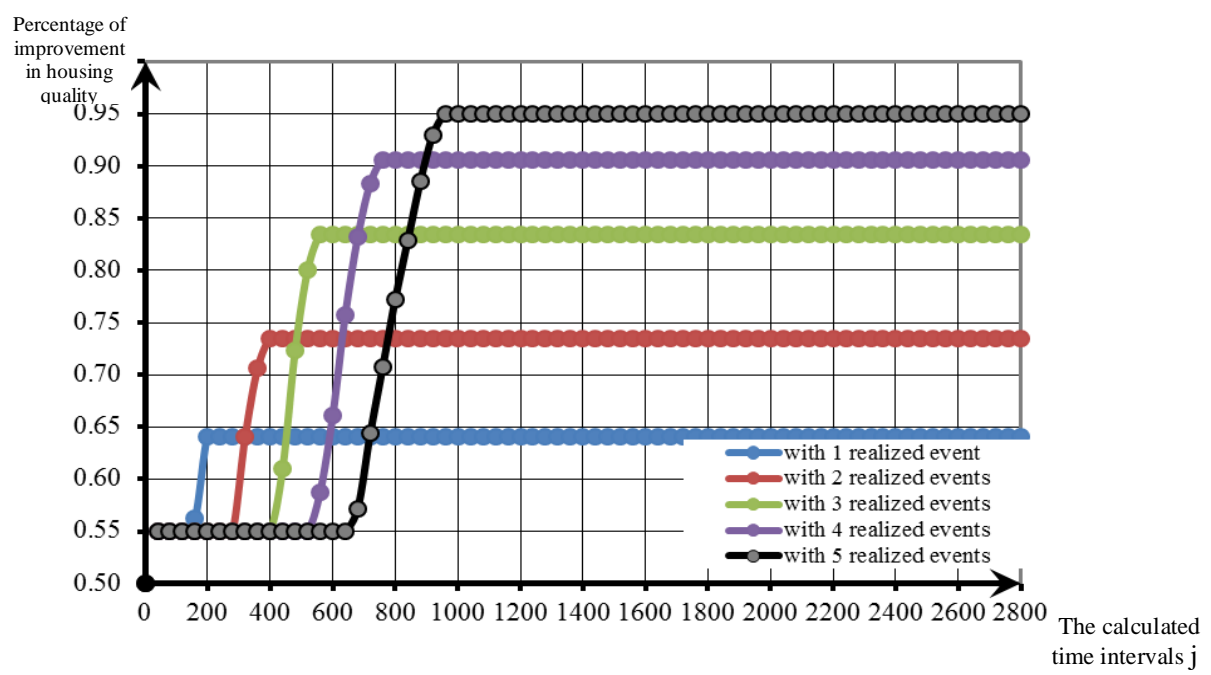

Fig. 4. Percentage of improvement in housing quality for various amounts of energy-saving measures implemented, based on the results of numerical experiments (graphs are spaced along the abscissa axis for better visibility)

The graph shows that the dynamics of increasing the percentage of improvement in the quality of housing is decreasing. When comparing 4 and 5 implemented measures, the percentage of improving the quality of housing increases by approximately 5 percent, and when implementing one energy-saving measure - $9 \%$.

The proposed algorithm allows determining the optimal distribution of funds. Input data for the calculation are selected from normative documents and statistical data on the dynamics of changes in the housing stock of the Karachay-Cherkess Republic. The results of the calculations are shown in the form of a diagram in figure 5.

\section{Discussion}

From the graphs presented in the paper (figure 2 and 3), it is clear that any process of energy modernization, consisting of a different number and quality of energy-saving measures, can be optimized on the basis of indicators of the amount of investment by allocating funds that lead to maximum economic effect.

The scheme of optimal allocation of funds for energy-saving measures is effective and has a number of advantages. 


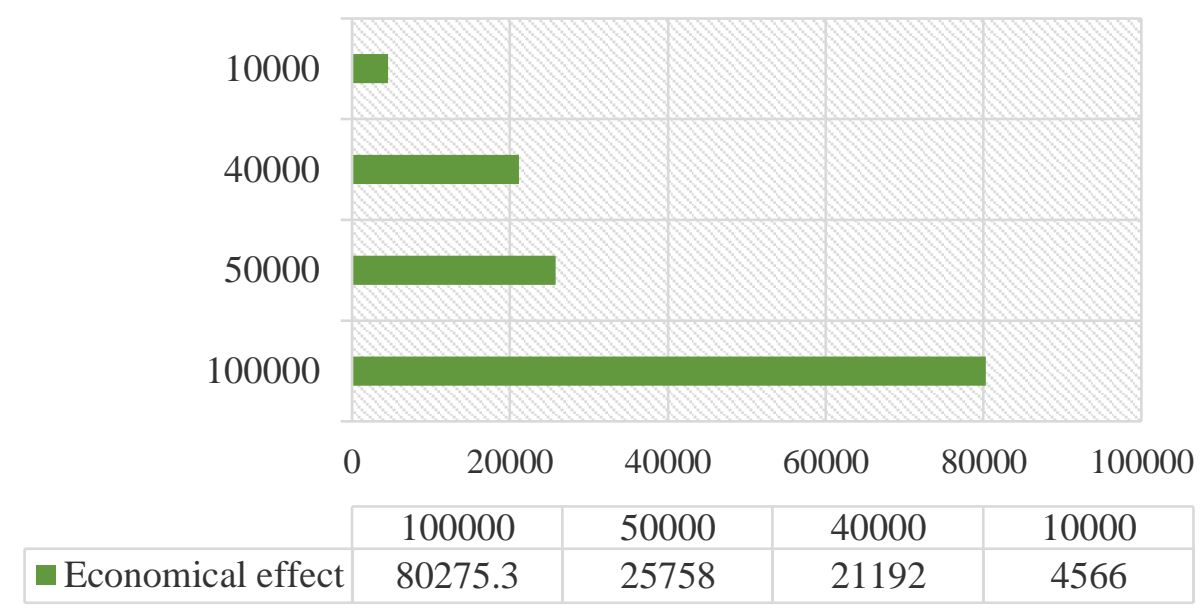

Economical effect, $P$

Fig. 5. Scheme of optimal allocation of allocated funds

First, according to the described scheme, the optimal management will be found, this solution will be obtained regardless of the number of steps and the initial stock of invested funds .

Second, the proposed method of comprehensive assessment of the effectiveness of energy-saving measures will improve the quality of decision-making on the restoration of the housing stock, increasing its energy efficiency.

The use of mathematical modeling methods will allow implementing projects for the distribution of financial resources in such a way that the implementation of organizational and technological solutions for the sequential implementation of measures in the housing sector will lead to the maximum positive social and economic effect.

\section{Conclusion}

Effective management of the housing stock renewal process is of particular importance at this moment.

In general, we can conclude that solving the housing problem is one of the priorities of the social and economic development of our country. Modernization, repair and reconstruction of housing stock should be considered not only as ways of reproduction that complement construction, but also as an alternative to it.

One of the most important factors that ensures the rational use of funds allocated to solve the housing problem is to prevent the absolutization of new housing construction and to take into account changes in the future of competitiveness of settlements.

The results of the study allow us to formulate the following conclusions:

It is established that the energy modernization of the housing stock leads to a decrease in the cost of citizens for housing and communal services, contributes to an increase in the integral indicator of comfort.

1. On the basis of the given scheme of dynamic planning of optimal allocation of funds for energy-saving measures, a generalized method of optimal management of the housing stock is implemented.

2. It was found that among the possible options for the management of energy 
modernization of housing stock will be uniquely selected optimum control regardless of the number of steps and the initial reserve of invested funds.

3. A mathematical model is proposed that allows maximizing the number of high-quality housing by implementing energy-saving and other measures for the modernization of the housing stock.

\section{References}

1. M.Lavagna, C. Baldassarri, A. Campioli, S. Giorgi, S. Sala. Building and Environment, 145, 260-275 (2018). https://doi.org/10.1016/j.buildenv.2018.09.008

2. L.Adua, B.Clark, R.York, C. Chen. Journal of Environmental Management, 252, 10965 (2019). https://doi.org/10.1016/j.jenvman.2019.109659

3. J.A. Bergendahla, J. Sarkisb, M.T. Timkoc. Resources, Conservation \& Recycling, 133, 309-319 (2018). https://doi.org/10.1016/j.jenvman.2019.109659

4. J.A. Bergendahl, J. Sarkisb, M.T. Timkoc. Resources, Conservation and Recycling, 133, 309-319 (2018). https://doi.org/10.1016/j.resconrec.2018.01.001

5. I. Giurca, I. Aşchilean, G.S. Naghiu, G. Badea. Procedia Technology, 22, 789-796 (2016). https://doi.org/10.1016/j.protcy.2016.01.050

6. N. Hritonenko, Y. Yatsenko. Energy Economics, 34, 1548-1556 (2012). https://doi.org/10.1016/j.eneco.2011.11.014

7. M.S. Geraldi, E. Ghisi. Energy and Buildings, 211, 109810 (2020) https://doi.org/10.1016/j.enbuild.2020.109810.

8. I. Kovacic, M. Summer, C. Achammer. Journal of Cleaner Production. 881,349-357 (2015). https://doi.org/10.1016/j.jclepro.2014.04.080

9. S. Copiello. Energy Policy. 85, 288-298 (2015). doi.org/10.1016/j.enpol.2015.06.017

10. Jin Xue. Environmental Development. 4, 18-35 (2012). https://doi.org/10.1016/j.envdev.2012.08.003

11. J. Ravetz. Energy Policy, 36, $4462-4470$ (2008). doi.org/10.1016/j.enpol.2008.09.026

12. P. M. Ward. International Encyclopedia of Housing and Home, 559-572 (2012). https://doi.org/10.1016/B978-0-08-047163-1.00232-0

13. S. Bayramukov, Z. Dolaeva, M. Kappusheva, Herald of Dagestan State Technical University. Technical Sciences. 43(4), 175-183 (2016). DOI:10.21822/2073-6185-201643-4-175-183

14. A. Chentsov, A. Chentsov. Reports of the Academy of Sciences. 453 (1). 20-23 (2013). DOI: $10.7868 / \mathrm{S} 0869565213230047$

15. V. Pukhkal. Procedia Engineering, 117, 616-623 (2015). doi.org/10.1016/j.proeng.2015.08.222 . 